\title{
Transesophageal Echocardiographic Detection of Cardiac Sources of Embolism in Elderly Patients with Ischemic Stroke
}

\author{
Hiroyuki Okura, Hiroo Inoue*, Miyo Tomon, Shoji NishiYama, Tadashi Yoshikawa and Kiyoshi Yoshida**
}

\begin{abstract}
Objective The aim of this study was to clarify the role of transesophageal echocardiography in detecting cardiac sources of embolism in elderly stroke patients. Methods We performed transesophageal echocardiography in 77 patients $\geq 70$ years old (mean 76.9) with ischemic stroke and investigated embolic sources. Thirty-seven patients were in sinus rhythm (SR) and 40 in atrial fibrillation (Af). Results Left atrial spontaneous echo contrast was detected in $73 \%$ of Af and in $14 \%$ of $S R(p<0.01)$. Left atrial thrombus was present in $10 \%$ of Af and none of $S R$ $(p<0.05)$. Patent foramen ovale, atrial septal aneurysm, and aortic atherosclerotic plaque $\geq 4.0$ $\mathbf{m m}$ in thickness in the proximal aortic arch were more commonly found in patients with SR. Conclusions In elderly ischemic stroke patients, 1) Left atrial spontaneous echo contrast and thrombus are more commonly detected in patients with Af, reflecting left atrial enlargement and blood stasis, and 2) atrial septal aneurysm, patent foramen ovale and aortic atherosclerotic plaque $\geq 4.0 \mathrm{~mm}$ in thickness in the proximal aortic arch are important findings in patients with SR.
\end{abstract}

(Internal Medicine 38: 766-772, 1999)

Key words: cerebral embolism, embolic source, diagnosis

\section{Introduction}

Recently, hemorrhagic stroke has remarkably decreased in Japan. However, the prevalence of ischemic stroke has shown a rather gradual decrease. Furthermore, the morbidity and mortality of ischemic stroke is still high and has increased with advancing age $(1,2)$. Therefore, it is still a major concern for us to determine how to prevent and manage elderly patients with ischemic stroke.

For editorial comment, see also p 753.

Previous reports suggest that 6-39\% of ischemic stroke are caused by cardiogenic emboli (3-8). Left atrial spontaneous echo contrast and thrombus formation associated with atrial fibrillation have been reported as one of the most important cardiac sources of embolism (9-13). Using transesophageal echocardiography, other possible sources of embolism including atrial septal aneurysm (14-19), patent foramen ovale (18, 20-27) and aortic atherosclerotic plaque (28-40) have been reported as independent risk factors of ischemic stroke. However, previous studies have not shown characteristics of an embolic source in an elderly patient with ischemic stroke. Therefore, we designed this study to characterize the sources of embolism in elderly ischemic stroke patients with both sinus rhythm and atrial fibrillation and to clarify the role of transesophageal echocardiographic examination in elderly patients.

\section{Subjects and Methods}

Between June 1995 and September 1997, we recruited patients older than age 70 years with "completed ischemic stroke" referred to the echocardiography laboratory of Kobe Rehabilitation Hospital for a transesophageal echocardiographic examination. The study group consisted of 77 consecutive patients (47 men and 30 women, age ranged 70 to 90 years, mean $76.9 \pm 4.4$ years). Thirty-seven patients were in sinus rhythm (SR) and 40 in atrial fibrillation (Af).

All patients underwent computed tomography (CT) imaging before echocardiographic examination to confirm the diagnosis of completed ischemic stroke. A completed ischemic stroke was defined as rapidly developing clinical signs of focal disturbance of cerebral function lasting longer than 24 hours

From the Department of Internal Medicine, Kobe Rehabilitation Hospital, Kobe, *the Department of Internal Medicine, Maikodai Hospital, Kobe and **the Division of Cardiology, Kobe General Hospital, Kobe

Received for publication July 13, 1998; Accepted for publication April 15, 1999

Reprint requests should be addressed to Dr. Hiroyuki Okura, Center for Research in Cardiovascular Interventions, Stanford University Medical Center, 300 Pasteur Drive, H3554, Stanford, CA 94305, USA 
with no apparent cause other than that of vascular origin, while CT showed an area of low attenuation compatible with the clinical signs and symptoms.

Transthoracic and transesophageal echocardiography with contrast study were performed. M-mode, two-dimensional and Doppler echocardiographic studies were performed with the patients in the left lateral decubitus position using a commercially available echocardiographic machine (Toshiba, SSH$160 \mathrm{~A}$, Tokyo) with 3.5- and 2.5-MHz phased-array transducer. All echo images were recorded on $0.5-\mathrm{in}$. (1.27-cm) SVHS video tape for subsequent analysis. Standard views including parasternal, apical and subcostal views were obtained in all patients.

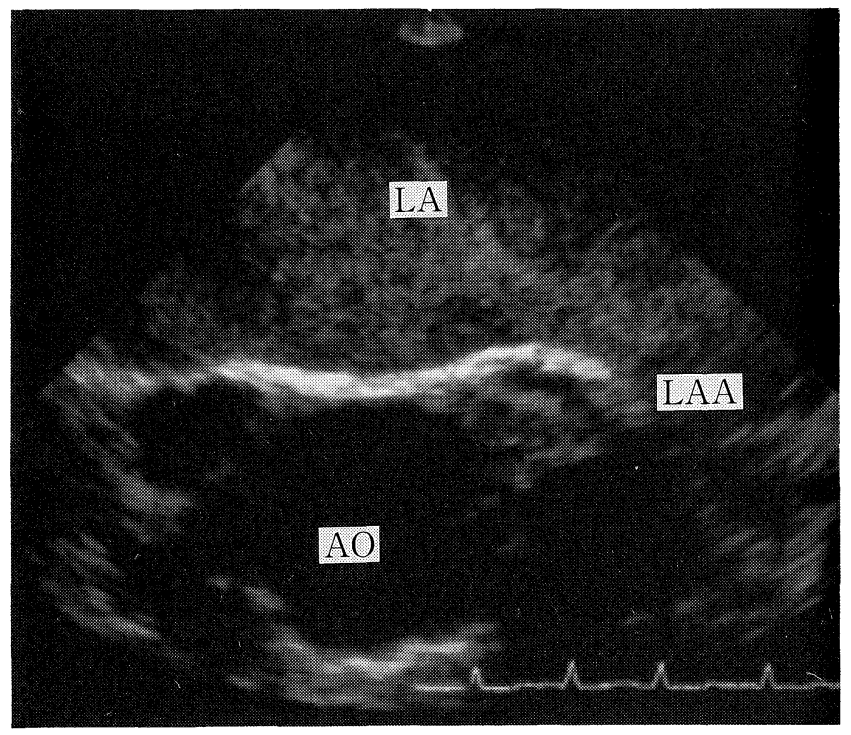

Figure 1. Transesophageal echocardiographic image demonstrating left atrial spontaneous echo contrast defined as "smoke-life" echoes swirling slowly in the left atrium. Ao: aorta, LA: left atrium, LAA: left atrial appendage.

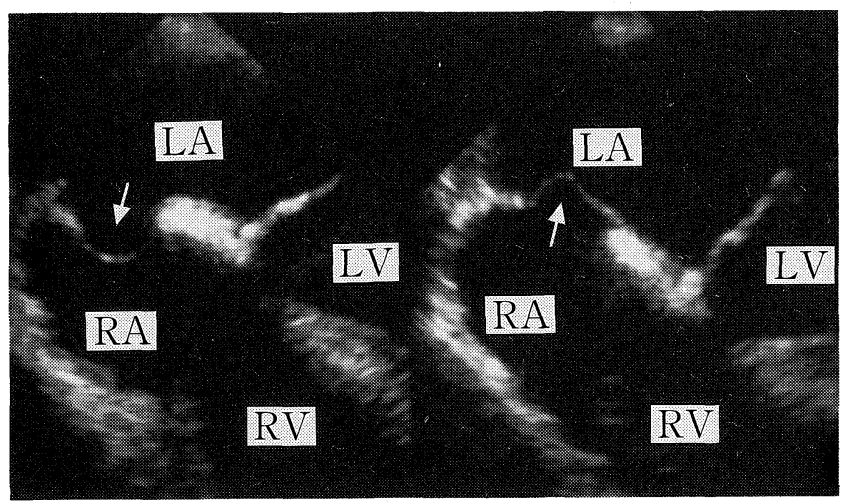

Figure 2. Transesophageal echocardiographic images of oscillating atrial septal aneurysm (arrow). LA: left atrium, RA: right atrium, $R V$ : right ventricle.
Transesophageal echocardiography was performed with a biplane 5-MHz phased array probe. The echocardiographic images were recorded on SVHS video tape for later analysis. After routine transesophageal echocardiographic examination of embolic sources, contrast echocardiography with saline injection during the Valsalva maneuver was also performed as previously reported (26). The following possible sources of embolism were investigated: 1) left atrial or left atrial append-

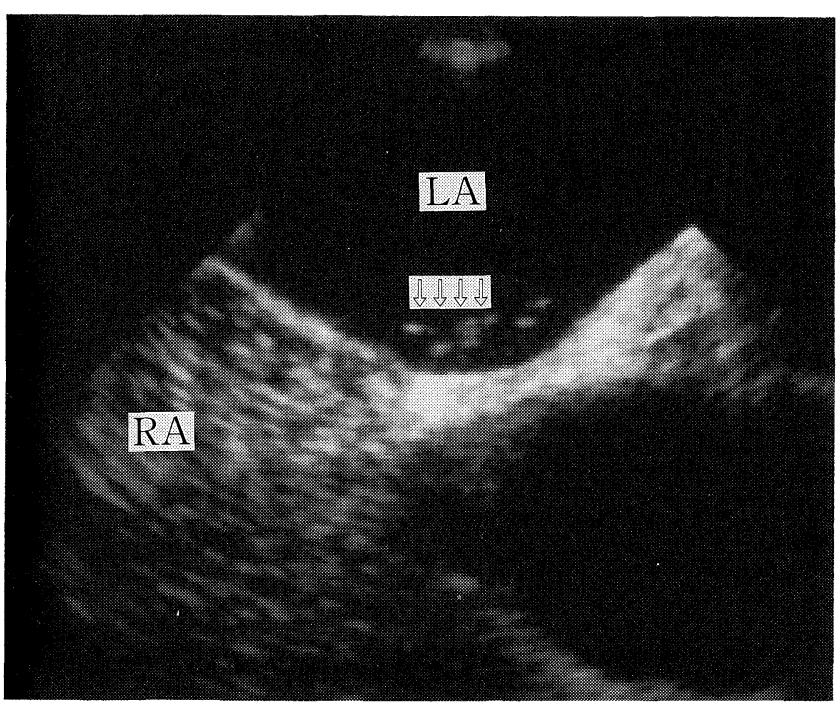

Figure 3. Transesophageal echocardiographic images of patent foramen ovale with right-to-left shunts. After intravenous injection of hand agitated saline, microcavitations appeares in the left atrium during Valsalva maneuver (arrows). LA: left atrium, RA: right atrium.

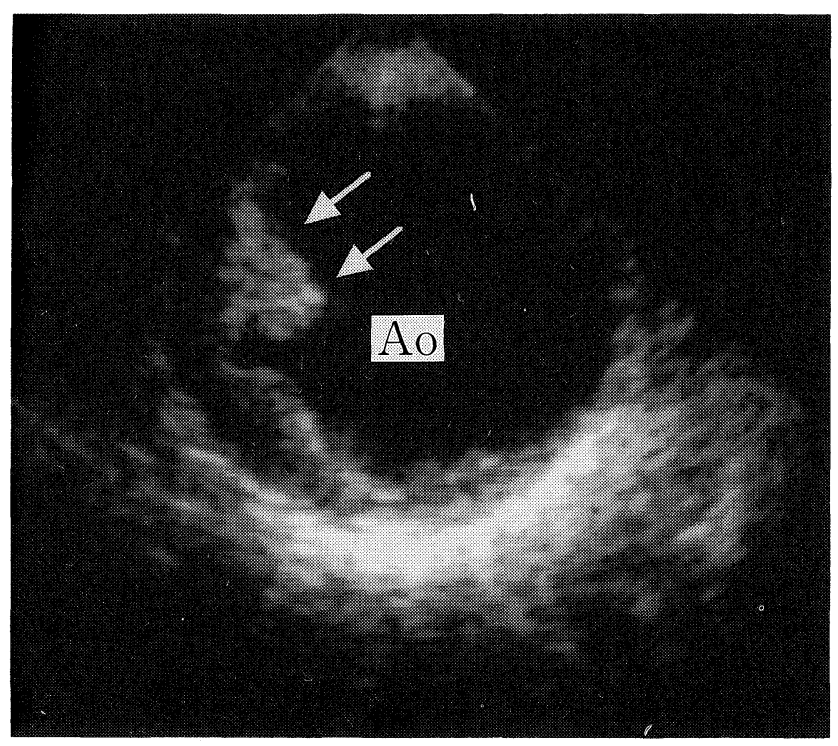

Figure 4. Transesophageal echocardiographic image of protruding atherosclerotic plaque in the aorta (arrows). Ao: aorta. 
age thrombus, 2) left atrial spontaneous echo contrast (defined as "smoke-like" echoes swirling slowly in the left atrium) (Fig. 1), 3) atrial septal aneurysm (defined as a protrusion of the aneurysm $>10 \mathrm{~mm}$ beyond the plane of the atrial septum into either the right or left atrium according to the published criteria (19) (Fig. 2), 4) patent foramen ovale (defined using contrast echocardiography based on the appearance of more than five microcavitations after the Valsalva maneuver into the left atrium within three cardiac cycle after intravenous injection of hand agitated saline) (Fig. 3), 5) left ventricular thrombus, 6) left atrial or ventricular tumor, 7) aortic or mitral valvular myxomatous thickening or vegetation, 8) aortic atherosclerotic plaque (AoP) $\geq 4.0 \mathrm{~mm}$ in thickness in the proximal aortic arch (Fig. 4). Left atrial diameter (LAD) measured by transthoracic echocardiography, and left atrial appendage flow velocity measured by transesophageal echocardiography were also analyzed. The carotid artery stenosis $\geq 70 \%$ was defined by either angiography, carotid echo or magnetic resonance angiography.

\section{Statistical analysis}

We used the chi-square test or Fisher's exact test for categorical variables to test significance of differences between two groups of patients. We used unpaired t test to compare the left atrial diameter and left atrial appendage flow velocity between two groups. A level of $p<0.05$ was considered to be statistically significant.

\section{Results}

Transesophageal echocardiography was safely performed in all patients. Clinical characteristics of the study patients are shown in Table 1. There were no differences in the prevalence of diabetes mellitus (group SR: 19\% vs group Af: $23 \%$, $\mathrm{p}=0.699$ ) and cigarette smoking (group SR: $30 \%$ vs group Af: $25 \%, \mathrm{p}=0.471$ ) between the two groups. However, hypertension (group SR: $65 \%$ vs group Af: $43 \%, \mathrm{p}<0.05$ ) and hyperlipidemia (group SR: $49 \%$ vs group Af: $25 \%$, p $<0.05$ ) were more common in patients with SR compared with Af. Total cholesterol levels were significantly higher in patients with sinus rhythm (group SR: $204.1 \pm 34.0$ vs group Af: $179.1 \pm 35.6$ $\mathrm{mg} / \mathrm{dl}, \mathrm{p}<0.01$ ). Serum triglyceride (group SR: $126.1 \pm 45.6$ vs group Af: $109.7 \pm 48.3 \mathrm{mg} / \mathrm{dl}, \mathrm{p}=0.150$ ) and HDL-cholesterol levels (group SR: $42.2 \pm 9.7$ vs group Af: $45.9 \pm 12.7 \mathrm{mg} / \mathrm{dl}$, $\mathrm{p}=0.177$ ) were not different between the two groups. In group Af, LAD measured by transthoracic M-mode echocardiography was significantly larger (group Af: $4.1 \pm 0.9$ vs group SR: $3.3 \pm 0.7$ $\mathrm{cm}, \mathrm{p}<0.01$ ) and left atrial appendage flow velocity was significantly lower (group Af: $33 \pm 21$ vs group SR: $64 \pm 27 \mathrm{~cm} / \mathrm{sec}$, $\mathrm{p}<0.01$ ) compared with group SR, respectively (Table 2 ).

The prevalences of the cardiac and vascular sources of embolism diagnosed by transthoracic and transesophageal echocardiography are shown in Table 2. Transthoracic echocardiography demonstrated cardiac abnormalities in 12 of $40(30 \%)$ patients with Af and in 14 of 37 (38\%) patients with SR. In 70 of 77 patients (91\%), transesophageal echocardiography revealed the following additional findings.

Left atrial spontaneous echo contrast was detected in 29 of $40(73 \%)$ patients with Af and 5 of $37(14 \%)$ patients with SR $(p<0.01)$. Left atrial thrombus was present in 4 of $40(10 \%)$ patients with Af and none of $\mathrm{SR}(\mathrm{p}<0.05)$. Patent foramen ovale was detected in 13 of $37(35 \%)$ patients with SR and 3 of 40 $(8 \%)$ patients with Af $(\mathrm{p}<0.01)$. Atrial septal aneurysm was found in 3 of 40 patients (8\%) with Af and 10 of 37 patients $(27 \%)$ with SR $(\mathrm{p}<0.05)$. Aortic atherosclerotic plaque $\geq 4.0 \mathrm{~mm}$ in thickness in the proximal aortic arch was found in 16 of 40 (40\%) patients with Af and 25 of 37 (68\%) patients with SR $(\mathrm{p}<0.05)$. Left ventricular thrombus, intracardiac tumor, or valvular masses were not detected in this study population.

\section{Discussion}

The present study demonstrates that in elderly patients with ischemic stroke transesophageal echocardiography reveals cardiac and vascular sources of embolism in majority of patients with both Af and SR. In patients with Af, left atrial spontaneous echo contrast and left atrial thrombus were more common

Table 1. Clinical Characteristics

\begin{tabular}{|c|c|c|c|c|}
\hline & & $\begin{array}{l}\text { Group Af } \\
(n=40)\end{array}$ & $\begin{array}{l}\text { Group SR } \\
(n=37)\end{array}$ & $\mathrm{p}$ value \\
\hline Age (years) & & $75.8 \pm 4.8$ & $78.1 \pm 3.7$ & $<0.05$ \\
\hline $\operatorname{BMI}\left(\mathrm{kg} / \mathrm{m}^{2}\right)$ & & $20.7 \pm 3.1$ & $21.4 \pm 2.5$ & 0.269 \\
\hline Smoking & - no. $(\%)$ & $10(25 \%)$ & $12(30 \%)$ & 0.471 \\
\hline Hypertension & - no. $(\%)$ & $17(43 \%)$ & $24(65 \%)$ & $<0.05$ \\
\hline Diabetes mellitus & - no. $(\%)$ & $9(23 \%)$ & $7(19 \%)$ & 0.699 \\
\hline Hyperlipidemia & - no. $(\%)$ & $10(25 \%)$ & $18(49 \%)$ & $<0.05$ \\
\hline $\begin{array}{l}\text { Carotid stenosis } \\
(\geq 70 \%)\end{array}$ & - -no. $(\%)$ & $3(8 \%)$ & $7(19 \%)$ & 0.121 \\
\hline Total cholesterol (mg/dl) & & $179.1 \pm 35.6$ & $204.1 \pm 34.0$ & $<0.01$ \\
\hline HDL-cholesterol (mg/dl) & & $45.9 \pm 12.7$ & $42.2 \pm 9.7$ & 0.177 \\
\hline Triglyceride (mg/dl) & & $109.7 \pm 48.3$ & $126.1 \pm 45.6$ & 0.150 \\
\hline
\end{tabular}

Af: atrial fibrillation, SR: sinus rhythm, BMI: body mass index. 
Table 2. Transthoracic and Transesophageal Echocardiography Findings

\begin{tabular}{lcccc}
\hline & & $\begin{array}{l}\text { Group Af } \\
(\mathrm{n}=40)\end{array}$ & $\begin{array}{l}\text { Group SR } \\
(\mathrm{n}=37)\end{array}$ & p value \\
\hline Transthoracic echocardiography & & & & \\
$\quad$ Valvular heart diseases & -no. $(\%)$ & $8(20 \%)$ & $6(16 \%)$ & 0.667 \\
Myocardial infarction & -no. $(\%)$ & $3(8 \%)$ & $5(14 \%)$ & 0.388 \\
Others & -no. $(\%)$ & $1(3 \%)$ & $3(8 \%)$ & 0.268 \\
LAD (cm) & & $4.1 \pm 0.9$ & $3.3 \pm 0.7$ & $<0.01$ \\
Transesophageal echocardiography & & & & \\
LASEC & -no. $(\%)$ & $29(73 \%)$ & $5(14 \%)$ & $<0.01$ \\
LATH & -no.(\%) & $4(10 \%)$ & $0(0 \%)$ & $<0.05$ \\
PFO & -no. $(\%)$ & $3(8 \%)$ & $13(35 \%)$ & $<0.01$ \\
ASA & -no. $(\%)$ & $3(8 \%)$ & $10(27 \%)$ & $<0.05$ \\
AoP ( $\geq 4.0$ mm) & -no.(\%) & $16(40 \%)$ & $25(68 \%)$ & $<0.05$ \\
LAA flow velocity (cm/sec) & & $33 \pm 21$ & $64 \pm 27$ & $<0.01$ \\
\hline
\end{tabular}

Af: atrial fibrillation, SR: sinus rhythm, LAD: left atrial diameter, LASEC: left atrial spontaneous echo contrast, LATH: left atrial thrombus, PFO: patent foramen ovale, ASA: atrial septal aneurysm, AoP: atherosclerotic plaque in the proximal aortic arch, LAA: left atrial appendage.

findings. On the other hand, atrial septal aneurysm, patent foramen ovale and atherosclerotic plaque in the proximal aortic arch were more frequently detected in patients with SR.

\section{Previous studies with transesophageal echocardiography}

Previous reports that compared transthoracic and transesophageal echocardiography in patients with stroke and transient ischemic attack showed the superiority of transesophageal echocardiography in detecting cardiac sources of embolism (41-51). Pop et al (42) studied 72 patients with transient ischemic attack or non-disabling stroke. They reported that transesophageal echocardiography defined morphologic abnormalities in $5(9 \%)$ of 53 patients without cardiac abnormalities on clinical examination and in $6(32 \%)$ of 19 patients with one or more clinical cardiac abnormalities. They also reported that in $32(44 \%)$ of 72 patients transesophageal echocardiography identified thoracic aortic atherosclerotic plaques. However, in their study, the prevalence of atrial septal aneurysm or patent foramen ovale was uncertain.

On the other hand, Lee et al reported that transesophageal echocardiography demonstrated at least one intracardiac abnormality, such as a left atrial or left atrial appendage thrombus, a patent foramen ovale, spontaneous echo contrast, and mitral valve strands in $26(52 \%)$ of 50 patients with a negative transthoracic echocardiogram for potential sources of emboli (44). Similarly, Rauh et al demonstrated that transesophageal echocardiography revealed left atrial appendage thrombus in 3 , atrial septal aneurysm in 2 , patent foramen ovale in 7 , and aortic plaque in 19 of 30 ischemic stroke patients with SR and normal transthoracic echocardiography and without carotid artery stenosis (46). In addition, they and other investigators have shown the utility of transesophageal echocardiography in therapeutic stratification of ischemic stroke patients $(46,48)$. Our results are consistent with these previous reports.

\section{Left atrial spontaneous echo contrast and thrombus}

Af with or without valvular heart diseases has been known as an important risk factor of ischemic stroke (5, 7, 52-55). Af is reported to present in up to $24 \%$ of all ischemic stroke and in almost half of cardioembolic stroke (7). Left atrial blood stasis represented by left atrial dilatation, the presence of left atrial spontaneous echo contrast and decreased left atrial appendage function have been reported to be associated with left atrial thrombus formation $(10-13,56)$. In the present study, we observed a larger left atrial dimension, a higher prevalence of the left atrial spontaneous echo contrast and a lower left atrial appendage flow velocity in elderly stroke patients with Af compared with those in SR. Interestingly, some authors reported that up to one-third of Af findings in ischemic stroke cases are coincidental (57). Our finding that sources of embolism not related to Af were detected in about $50 \%$ of patients with Af may support their observation.

\section{Atrial septal aneurysm and patent foramen ovale}

Patent foramen ovale was found in 27 to $35 \%$ of autopsy series $(58,59)$. However, using transthoracic or transesophageal contrast echocardiography, patent foramen ovale has been reported to be present in only 3.2 to $22 \%$ (average: $12 \%$ ) of normal subjects $(18,20-26)$. The reason for the lower prevalence of patent foramen ovale compared with autopsy series is uncertain. Lechat et al speculated that left atrial pressure may remain higher than the right atrial pressure after Valsalva maneuver in some patent foramen ovale cases (20). Webster et al suggested that half of these patent foramen ovale cases in autopsy series were too small to be detected by contrast method (21). Early studies using transthoracic contrast echocardiography described a high incidence of patent foramen ovale in young stroke patients compared with control subjects $(20,21)$. Although the prevalence was not as high as in the younger 
patients, patent foramen ovale has been detected in all age groups more often than in the control group $(22,23,26)$. However in the very elderly patients group, the significance of patent foramen ovale as a possible source of emboli has not been clarified. We found that the overall prevalence of patent foramen ovale in the current study was similar to that previously reported in all age groups and the prevalence was higher in patients with SR (37\%) than in patients with Af (11\%).

Atrial septal aneurysm with or without patent foramen ovale has also been considered as an independent risk factor of arterial embolism, although the mechanism of thrombus formation has not been clarified (14-19). Meta-analysis of published transesophageal echocardiography studies demonstrated that the frequency of atrial septal aneurysm was on average $8.8 \%$ of patients with cerebral and/or peripheral embolism (60). The prevalence and significance of atrial septal aneurysm as well as patent foramen ovale in elderly stroke patients remain uncertain. In the present study, atrial septal aneurysm was detected at the same or at a higher frequency in elderly stroke patients with SR than can be expected from previous studies including whole age groups.

These results suggest that atrial septal aneurysm and patent foramen ovale may play some role as possible sources of embolism in elderly patients with sinus rhythm and should be investigated as well as in younger patients.

\section{Aortic atherosclerotic plaque}

We also showed a high incidence of atherosclerotic plaque in the aortic arch both in patients with SR and Af. Recently, atherosclerotic plaque in the aorta has become easily visualized using transesophageal echocardiography. Several investigators have reported a strong association between atherosclerotic plaque of the aorta and ischemic stroke (28-40). Karalis and coworkers found intraaortic atherosclerotic debris (plaque) in $38(7 \%)$ of 556 patients undergoing transesophageal echocardiography (28). They observed an embolic event in 11 (31\%) of 36 study patients with intraaortic atherosclerotic debris. Tunick et al compared 122 stroke patients with control subjects (29). They found that the presence of protruding atheromas in the thoracic aorta was strongly related to the occurrence of embolic symptoms. Amarenco et al also reported that atherosclerotic plaques $\geq 4 \mathrm{~mm}$ in the ascending or proximal aortic arch were found in $36(14.4 \%)$ of 250 patients with stroke but in only 5 (2\%) of 250 control subjects (34). They concluded that atherosclerotic disease of the aortic arch should be considered as a risk factor and a possible source of embolism for ischemic stroke. The same investigators recently reported that stroke patients with atherosclerotic plaque $\geq 4 \mathrm{~mm}$ in the ascending or proximal aortic arch had a higher incidence (11.9 per 100 person-years) of recurrent brain infarction as compared with 3.5 person-years in patients with a wall thickness of 1 to $3.9 \mathrm{~mm}$ and 2.8 per 100 person-years in patients with a wall thickness of $<1 \mathrm{~mm}$ (40). In the current study, we found a higher incidence of atherosclerotic plaques $\geq 4 \mathrm{~mm}$ in the ascending aorta or proximal aortic arch especially in patients with SR. Furthermore, transesophageal echocardiography detected other possible cardiac sources of embolism, such as atrial septal aneurysm and patent foramen ovale, in $12(48 \%)$ of 25 patients with aortic atherosclerotic plaque in group SR and in $2(13 \%)$ of 16 patients in group Af. It is still not clear whether the coexistence of aortic atherosclerotic plaque in the aortic arch and other cardiac sources of embolism causes a higher risk for ischemic stroke. Future follow up studies with large numbers of patients are necessary to answer this question.

The present study has several limitations. First, we investigated a relatively small number of patients in each group without a normal control group. However, it is ethically difficult to examine apparently normal subjects age $\geq 70$. Even if we had served other elderly patients with various cardiac diseases referred to transesophageal echocardiographic examination as a control, it would not have been the true control group. Secondly, although transesophageal echocardiographic examination altered the therapy in some patients with Af, the impact of transesophageal echocardiography on the therapeutic strategies in stroke patients with SR is still unknown. Ongoing controlled prospective studies will clarify the role of anticoagulation, antiplatelet therapy, or surgical intervention in patients with atrial septal aneurysm, patent foramen ovale or atherosclerotic plaque. Finally, since this is a retrospective, single center study, a prospective study with larger numbers may be necessary to confirm our preliminary observation.

In conclusion, transesophageal echocardiography demonstrates various cardiac or vascular sources of embolism in elderly patients with ischemic stroke as it does in younger patients. Left atrial spontaneous echo contrast or thrombus is a more common finding in patients with Af. On the other hand, atrial septal aneurysm, patent foramen ovale and aortic atherosclerotic plaque $\geq 4.0 \mathrm{~mm}$ in thickness in the proximal aortic arch were more frequently detected in patients with SR. Whether the presence of multiple embolic sources may increase the risk of stroke and some therapeutic strategies including anticoagulation, antiplatelets, and surgical approaches can improve their prognosis remains to be studied.

Acknowledgements: We gratefully thank Dr. Mutsumi Okura, a neurologist, for her valuable clinical advice and assistance throughout the preparation of this manuscript. We also acknowledge the technical assistance of Yasuko Yabuta, the sonographer, for performing transthoracic and transesophageal echocardiography in this study.

\section{References}

1) Ueda $K$, Omae $T$, Hirota $Y$, et al. Decreasing trend in incidence and mortality from stroke in Hisayama residents, Japan. Stroke 12: 154-160, 1981.

2) Suzuki K, Kutsuzawa T, Takita K, et al. Clinico-epidemiologic study of stroke in Akita, Japan. Stroke 18: 402-406, 1987.

3) Mohr JP, Caplan LR, Melski JW, et al. The Harvard Cooperative Stroke Registry: a prospective registry. Neurology 28: 754-762, 1978.

4) Caplan LR, Hier D, D'Cruz I. Cerebral embolism in the Michael Rese Stroke Registry. Stroke 14: 530-537, 1982.

5) Wolf PA, Kannel WB, McGee DL, Meeks SL, Bharucha NE, McNamara PM. Duration of atrial fibrillation and imminence of stroke: the Framingham study. Stroke 14: 664-667, 1983.

6) Bogousslavsky J, Van Melle G, Regli F. The Lausanne Stroke Study: analysis of 1000 consecutive patients with first stroke. Stroke 19: 1083-1092, 


\section{Embolic Sources by TEE in Elderly Stroke}

1988.

7) Asinger EW, Dyken ML, Fisher M, Hart RG, Sherman DG. Cardiogenic brain embolism: the second report of the cerebral embolism task force. Arc Neurol 46: 727-743, 1989.

8) Hart RG. Cardiogenic embolism to the brain. Lancet 339: 589-594, 1992.

9) Sage JI, Van Uitert RL. Risk of recurrent stroke in patients with atrial fibrillation and non-valvular heart disease. Stroke 14: 537-540, 1983.

10) Daniel WG, Nellessen U, Schröder E, et al. Left atrial spontaneous echo contrast in mitral valve disease: an indicator for an increased thromboembolic risk. J Am Coll Cardiol 11: 1204-1211, 1988.

11) Brickner ME, Friedman DB, Cigarroa CG, Grayburn PA. Relation of thrombus in the left atrial appendage by transesophageal echocardiography to clinical risk factors for thrombus formation. Am J Cardiol 74: 391393, 1994.

12) Fatkin D, Kelly RP, Feneley MP. Relation between left atrial appendage blood flow velocity, spontaneous echocardiographic contrast and thromboembolic risk in vivo. J Am Coll Cardiol 23: 961-969, 1994.

13) Santiago D, Warshofsky M, Li Mandri G, et al. Left atrial appendage function and thrombus formation in atrial fibrillation-flutter: a transesophageal echocardiographic study. J Am Coll Cardiol 24: 159164, 1994.

14) Gallet B, Malergue MC, Adams C, et al. Atrial septal aneurysm- a potential cause of systemic embolism. An echocardiographic study. Br Heart J 53: 292-297, 1985.

15) Schneider B, Hanrath $P$, Vogel $P$, Meinertz T. Improved morphologic characterization of atrial septal aneurysm by transesophageal echocardiography: relation to cerebrovascular events. J Am Coll Cardiol 16: 10001009, 1990.

16) Pearson AC, Nagelhout D, Castello R, Gomez CR, Labovitz AJ. Atrial septal aneurysm and stroke: a transesophageal echocardiographic study. J Am Coll Cardiol 18: 1223-1229, 1991.

17) Zabalgoitia-Reyes M, Herrerra C, Ghandhi DK, Mehlman DJ, McPherson DD, Talano JV. A possible mechanism for neurologic ischemic events in patients with atrial septal aneurysm. Am J Cardiol 66: 761-764, 1990.

18) Cabanes L, Mas JL, Cohen A, et al. Atrial septal aneurysm and patent foramen ovale as risk factors for cryptogenic stroke in patients less than 55 years of age. A study using transesophageal echocardiography. Stroke 24: 1865-1873, 1993.

19) Mügge A, Daniel WG, Angermann C, et al. Atrial septal aneurysm in adult patients: a multicenter study using transthoracic and transesophageal echocardiography. Circulation 91: 2785-2792, 1995.

20) Lechat P, Mas JL, Lascault G, et al. Prevalence of patent foramen ovale in patients with stroke. N Engl J Med 318: 1148-1152, 1988.

21) Webster MW, Chancellor AM, Smith $\mathrm{HJ}$, et al. Patent foramen ovale in young stroke patients. Lancet 2: 11-12, 1988.

22) Di Tullio M, Sacco RL, Gopal A, Mohr JP, Homma S. Patent foramen ovale as a risk factor for cryptogenic stroke. Ann Intern Med 117: 461$465,1992$.

23) de Belder MA, Tourikis L, Leech G, Camm J. Risk of patent foramen ovale for thromboembolic events in all age groups. Am J Cardiol 69: 1316-1320, 1992.

24) Hausmann D, Mügge A, Becht I, Daniel WG. Diagnosis of patent foramen ovale by transesophageal echocardiography and association with cerebral and peripheral embolic events. Am J Cardiol 70: 668-672, 1992.

25) Van Camp G, Schulze D, Cosyns B, Vandenbossche JL. Relation between patent foramen ovale and unexplained stroke. Am J Cardiol 71: 596-598, 1993.

26) Homma S, Di Tullio MR, Sacco RL, Mihalatos D, Li Mandri G, Mohr JP. Characteristics of patent foramen ovale associated with cryptogenic stroke. A biplane transesophageal echocardiographic study. Stroke 25: 582-586, 1994.

27) Hanna JP, Sun JP, Furlan AJ, Stewart WJ, Sila CA, Tan M. Patent foramen ovale and brain infarction. Echocardiographic predictors, recurrence, and prevention. Stroke 25: 782-786, 1994.

28) Karalis DG, Chandrasekaran K, Victor MF, Ross JJ, Mintz GS. Recognition and embolic potential of intraaortic atherosclerotic debris. J Am Coll Cardiol 17: 73-78, 1991.
29) Tunick PA, Perez JL, Kronzon I. Protruding atheromas in the thoracic aorta and systemic embolization. Ann Intern Med 115: 423-427, 1991.

30) Mitchell MM, Frankville DD, Weinger MB, Dittrich HC. Detection of thoracic aortic atheroma with transesophageal echocardiography in patients without symptoms of embolism. Am Heart J 122: 1768-1771, 1991.

31) Amarenco P, Duyckaerts C, Tzourio C, Hénin D, Bousser MG, Hauw J-J. The prevalence of ulcerated plaque in the aortic arch in patients with stroke. N Engl J Med 326: 221-225, 1992.

32) Katz ES, Tunick PA, Rusinek H, Ribakove G, Spencer FC, Kronzon I. Protruding aortic atheromas predict stroke in elderly patients undergoing cardiopulmonary bypass: Experience with intraoperative transesophageal echocardiography. J Am Coll Cardiol 20: 70-77, 1992.

33) Amarenco P, Cohen A, Baudrimont M, Bousser MG. Transesophageal echocardiographic detection of aortic arch disease in patients with cerebral infarction. Stroke 23: 1005-1009, 1992.

34) Amarenco P, Cohen A, Tzourio C, et al. Atherosclerotic disease of the aortic arch and the risk of ischemic stroke. N Engl J Med 331: 14741479, 1994.

35) Dávila-Román VG, Barzilai B, Wareing TH, Murphy SF, Schechtman $\mathrm{KB}$, Kouchoukos NT. Atherosclerosis of the ascending aorta. Prevalence and role as an independent predictor of cerebrovascular events in cardiac patients. Stroke 25: 2010-2016, 1994.

36) Nihoyannopoulos P, Joshi J, Athanasopoulos G, Oakley CM. Detection of atherosclerotic lesions in the aorta by transesophageal echocardiography. Am J Cardiol 71: 1208-1212, 1993.

37) Stone DA, Hawke MW, LaMonte M, et al. Ulcerated atherosclerotic plaques in the thoracic aorta are associated with cryptogenic stroke: A multiplane transesophageal echocardiographic study. Am Heart J 130: 105-108, 1995.

38) Jones EF, Kalman JM, Calafiore P, Tonkin AM, Donnan GA. Proximal aortic atheroma. An independent risk factor for cerebral ischemia. Stroke 26: $218-224,1995$.

39) Demopoulos LA, Tunik PA, Bernstein NE, Perez JL, Kronzon I. Protruding atheromas of the aortic arch in symptomatic patients with carotid artery disease. Am Heart J 129: 40-44, 1995.

40) The French Study of Aortic Plaque in Stroke Group. Atherosclerotic disease of the aortic arch as a risk factor for recurrent ischemic stroke. $\mathrm{N}$ Engl J Med 334: 1216-1221, 1996.

41) Zenker G, Erbel R, Kramer G, et al. Transesophageal two-dimensional echocardiography in young patients with cerebral ischemic events. Stroke 19: 345-348, 1988.

42) Pop G, Sutherland GR, Koudstaal PJ, Sit TW, de Jong G, Roelandt JR. Transesophageal echocardiography in the detection of intracardiac embolic sources in patients with transient ischemic attacks. Stroke 21: 560$565,1990$.

43) Hofmann T, Kasper W, Meinertz T, Geibel A, Just H. Echocardiographic evaluation of patients with clinically suspected arterial emboli. Lancet 336: 1421-1424, 1990.

44) Lee RL, Bartzokis T, Yeoh TK, Grogin HR, Choi D, Schnittger I. Enhanced detection of intracardiac sources of cerebral emboli by transesophageal echocardiography. Stroke 22: 734-739, 1991.

45) Pearson AC, Labovitz AJ, Tatineni S, Gomez CR. Superiority of transesophageal echocardiography in detecting cardiac source of embolism in patients with cerebral ischemia of uncertain etiology. J Am Coll Cardiol 17: 66-72, 1991.

46) Rauh R, Fischereder M, Spengel FA. Transesophageal echocardiography in patients with focal cerebral ischemia of unknown cause. Stroke 27: 691-694, 1996.

47) Cujec B, Polasek P, Voll C, Shuaib A. Transesophageal echocardiography in the detection of potential cardiac sources of embolism in stroke patients. Stroke 22: 727-733, 1991.

48) Hata JS, Ayres RW, Biller J, et al. Impact of transesophageal echocardiography on the anticoagulation managements of patients admitted with focal cerebral ischemia. Am J Cardiol 72: 707-710, 1993.

49) Labovitz AJ, Camp A, Castello R, et al. Usefulness of transesophageal echocardiography in unexplained cerebral ischemia. Am J Cardiol 72: 1448-1452, 1993. 


\section{OKuRA et al}

50) Albers GW, Comess KA, DeRook FA, et al. Transesophageal echocardiographic findings in stroke subtypes. Stroke 25: 23-28, 1994.

51) Comess KA, deRook FA, Beach KW, Lytle NJ, Golby AJ, Albers GW. Transesophageal echocardiography and carotid ultrasound in patients with cerebral ischemia: prevalence of findings and recurrent stroke risk. J Am Coll Cardiol 23: 1598-1603, 1994.

52) Wolf PA, Abbott RD, Kannel WB. Atrial fibrillation as an independent risk factor for stroke: the Framingham Study Stroke 22: 983-988, 1991.

53) Sherman DG, Goldman L, Whiting RB, Jurgensen K, Kaste M, Easton JD. Thromboembolism in patients with atrial fibrillation. Arc Neurol 41: 708-710, 1984.

54) Kannel WB, Abbott RD, Savage DD, McNamara PM. Epidemiologic features of chronic atrial fibrillation: the Framingham study. N Engl J Med 306: 1018-1022, 1982.

55) Jorgensen HS, Nakayama H, Reith J, Raaschou HO, Olsen TS. Acute stroke with atrial fibrillation. The Copenhagen Stroke Study. Stroke 27: 1765-1769, 1996.

56) Pollick C, Taylor D. Assessment of left atrial appendage function by transesophageal echocardiography. Implications for the development of thrombus. Circulation 84: 223-231, 1991.

57) van Merwijk G, Lodder J, Bamford J, Kester AD. How often is nonvalvular atrial fibrillation the cause of brain infarction? J Neurol 237: 205-207, 1990.

58) Hagen PT, Scholz DG, Edwards WD. Incidence and size of patent foramen ovale during the first 10 decades of life. An autopsy study of 965 normal hearts. Mayo Clin Proc 59: 17-20, 1984.

59) Thompson T, Evans W. Paradoxical embolism. Quart J Med 23: 135$150,1930$.

60) Mügge A, Daniel WG. Cardiogenic Embolism. Williams \& Wilkins Co, Baltimore, 1996: 159-168. 